\title{
FAKTOR RISIKO KEJADIAN ISPA PADA BALITA DI DESA BALEREJO KECAMATAN BALEREJO KABUPATEN MADIUN TAHUN 2015
}

\author{
Ninik Santika Dewi, Djoko Windu P. Irawan, Denok Indraswati
}

\begin{abstract}
ABSTRAK
Gangguan kesehatan yang biasanya ditimbulkan oleh buruknya kondisi lingkungan rumah adalah ISPA. Penderita ISPA paling banyak adalah balita, karena kekebalan tubuhnya yang masih rendah. Kondisi lingkungan fisik rumah seperti jenis lantai, jenis dinding, luas ventilasi, kepadatan hunian, kelembaban, suhu, pencahayaan dan pertukaran udara.

Tujuan penelitian ini menganalisis hubungan lingkungan fisik rumah dengan kejadian ISPA pada balita di Ds. Balerejo Kec. Balerejo Kab. Madiun.

Jenis penelitiancase control. pengumpulan data melalui wawancara, observasi dan pengukuran di rumah responden. Jumlah sampel 67 responden, jumlah penderita 50 balita dan kontrol 17 balita. Teknik pengambilan sampel untuk kasus menggunakan total sampling dan control dengan teknik random sampling, selanjutnya dianalisis dengan ujichi square.

Hasil analisis data menunjukkan bahwa jenis lantai, dinding, luas ventilasi, kelembaban, suhu, pencahayaan dan pertukaran udara ada hubungan kejadian ISPA. Kepadatan hunian tidak ada hubungan kejadian ISPA. Secara keseluruhan, lingkungan fisik rumah ada hubungan dengan kejadian ISPA pada balita.

Kesimpulan ada hubungan antara lingkungan fisik rumah dengan kejadian ISPA pada balita. Disarankan agar dilakukan penyuluhan mengenai kesehatan rumah dan faktor-faktor yang mengakibatkan penyakit berbasis lingkungan. Masyarakat disarankan membiasakan membuka jendela rumah agar sinar matahari dapat masuk dan pertukaran udara dapat terjadi dengan baik.

Kata Kunci : Lingkungan Fisik Rumah dan ISPA.
\end{abstract}

\section{PENDAHULUAN}

Salah satu lingkungan yang berpengaruh terhadap kesehatan manusia adalah rumah. Rumah sehat adalah bangunan rumah tinggal yang memenuhi persyaratan kesehatanmemiliki jamban yang sehat, sarana air bersih, tempat pembuangan sampah, sarana pembuangan air limbah, ventilasi rumah yang baik, kepadatan hunian yang sesuai dan lantai rumah yang tidak terbuat dari tanah (Notoatmodjo, S., 2003).

Penyakit berbasis lingkungansudah menjadi masalah utama dalamlingkungan masyarakat. Apalagi ditunjang dengan sarana sanitasi yangburuk yang ada di lingkunganmasyarakat. Hal ini dapat memicu agent penyebab penyakit dapat berkembang biak sehingga masyarakatterancam terkena penyakit (Wawan, A., \& Dewi Maria, 2010). Penyakit Infeksi Saluran Pernafasan Akut (ISPA) merupakan salah satu masalah kesehatan yang utama di Indonesia karena masih tingginya angka kejadian ISPA terutama pada anak Balita. ISPA mengakibatkan sekitar 20\% - 30\% kematian anak Balita (Notoatmodjo, S. 2007).

Desa Balerejo merupakan desa yang secara geografis berada di dataran rendah, terletak di pinggir jalan raya jalur antar propinsi yang padat lalu lintas, jarak rumah $\pm 5 \mathrm{~m}$ dari jalan raya dengan polusi udara yang tinggi. Pencemaran udara dalam ruang (indoor air pollution) sangat berbahaya bagi kesehatan, karena pada umumnyaorang lebih banyak menghabiskan waktu untuk melakukan kegiatandi dalam rumah sehingga rumah menjadi sangat penting sebagailingkungan mikro yang berkaitan dengan risiko dari pencemaranudara. Polusi udara akan memperburuk kondisi saluran pernafasan, sehingga mekanisme pertahanannyapun akan terganggu. Hal ini akan mempermudah terjadinya ISPA (Departemen Kesehatan RI, 2002).

Hasil identifikasi data Puskesmas, jumlah penyakit berbasis lingkungan tertinggi di wilayah kerja Puskesmas Balerejo pada tahun 2013 mulai bulan Januari sampai bulan Desember adalah penyakit ISPA balita. Frekuensi kejadian tertinggi 50 kasus dengan proporsi 0,15\% (Profil Kesehatan Dinas Kesehatan Kabupaten Madiun, 2012).

\section{TUJUAN PENELITIAN}

Menganalisis hubungan lingkungan fisik rumah dengan kejadian ISPA pada balita di Desa Balerejo Kecamatan Balerejo Kabupaten Madiun

\section{METODE PENELITIAN}

Jenis penelitian analitik observasional, mengisyaratkan cenderung melihat kasus 
kemudian mencoba mencari pembanding kontrol (Notoatmodjo,2005)

Objek penelitian adalah seluruh balita di Desa Balerejo yang pernah berobat di Puskesmas Balerejo dan dinyatakan menderita ISPA. Terdata sebanyak 50 orang balita dengan kriteria sampel: berusia 1-5 tahun, dinyatakan menderita ISPA.

Variabel penelitian adalah lingkungan fisik rumah yang meliputi jenis lantai, dinding, luas ventilasi, tingkat kepadatan hunian, tingkat kelembaban, suhu, pencahayaan dan pertukaran udara rumah, dan kejadian ISPA.

Analisis data secara Deskriptif dan dengan tabel silang $2 \times 2$ untuk menghitung nilai odds rasio. Uji statistik yang digunakan chi square dengan menggunakan a $5 \%$.

Hipotesis: ada hubungan antara keadaan lingkungan fisik rumah dengan kejadian ISPApada balita di Desa Balerejo Wilayah Kerja Puskesmas Balerejo Kabupaten Madiun.

\section{HASIL dan PEMBAHASAN}

\section{Kondisi Fisik Rumah}

Jenis lantai: Hasil observasi rumah responden berdasar jenis lantai dari 67 responden, $45(67,1 \%)$ rumah tidak memenuhi persyaratan kesehatan, hal ini dikarenakan rata-rata lantai rumah responden masih dari tanah dan belum kedap air.

Lantai dari tanah lebih baik tidak digunakan lagi, sebab bila musim hujan akan lembab sehingga dapat menimbulkan gangguan/penyakit terhadap penghuninya. Oleh karena itu perlu dilapisi dengan lapisan yang kedap air (semen, tegel, teraso, keramik dll), untuk mencegah masuknya air ke dalam rumah sebaiknya lantai dinaikkan kira-kira $20 \mathrm{~cm}$ dari permukaan tanah (Ditjen PPM dan PL, 2002).

Jenis dinding: Hasil observasi rumah responden berdasar jenis dinding 67 responden $41 \quad(61,1 \%)$ rumah tidak memenuhi persyaratan kesehatan, hal ini dikarenakan rata-rata rumah responden dinding rumahnya terbuat dari bahan bambu dan kayu, termasuk kategori tidak memenuhi persyaratan kesehatan. Sedangkan $26 \quad(38,9 \%)$ memenuhi persyaratan dengan jenis dinding permanen yaitu tembok. Fungsi dinding selain sebagai pendukung rumah juga untuk melindungi penghuni rumah dari serangga, hujan dan angin, juga melindungi dari panas dan angin luar. Konstruksi rumah dan lingkungan yang tidak memenuhi syarat kesehatan merupakan faktor resiko sumber penularan jenis penyakit (Ditjen PPM dan PL, 2012).
Luas ventilasi: Hasil observasi rumah responden berdasar luas ventilasi dari 67 responden $34 \quad(50,7 \%)$ rumah tidak memenuhi persyaratan kesehatan, dengan rata-rata luas ventilasi setiap rumah 2,17 $\mathrm{m}^{2}$ dan yang memenuhi syarat $4,91 \mathrm{~m}^{2}$ jumlah 33 rumah.

Pertukaran hawa (ventilasi) yaitu proses penyediaan udara segar dan pengeluaran udara kotor secara alamiah atau mekanis harus cukup, Luas dari jendela/lubang hawa sekurang-kurangnya $1 / 10$ dari luas lantai ruang. Luas penghawaan atau ventilasi alamiah yang permanen minimal $10 \%$ dari luas lantai (Ditjen PPM dan PL, 2012).

Tingkat kepadatan penghuni: Hasil observasi rumah responden berdasar tingkat kepadatan hunian 67 responden 57 $(85,1 \%)$ rumah sudah memenuhi persyaratan kesehatan dan 10 (14,9\%) rumah tidak memenuhi persyaratan kesehatan. Rata-rata dari 67 rumah dalam 1 rumah paling tidak 4 orang per luas rumah.

Kepadatan hunian yang baik dan memenuhi persyaratan adalah dengan luasan ruangan $8 \mathrm{~m}^{2}$ per penghuni dan tidak boleh digunakan lebih dari 2 orang.Ruangan yang terlalu sempit dapat menghambat pertukaran udara (Ditjen PPM dan $\mathrm{PL}, 2012$ ).

Kelembaban: hasil observasi rumah responden berdasar tingkat kelembaban dari 67 responden 33 (49,3\%) rumah tidak memenuhi persyaratan kesehatan. Ratarata dari 67 responden kelembaban di rumah yang tidak memenuhi syarat $71,35 \%$ dan rumah yang memenuhi syarat kelembabannya $64,3 \%$. Sedangkan 34 $(49,3 \%)$ rumah sudah memenuhi persyaratan, kelembaban yang sesuai berkisar antara 40-60\% kelembaban yang rendah/kering dapat disebabkan sistem sirkulasi yang buruk sedangkan kelembaban yang tinggi akibat sedikit sekali sinar matahari yang masuk ke dalam rumah. Kualitas udara dalam rumah tidak melebihi ketentuan kelembaban udara berkisar 40\%-70\% (Kepmenkes, 1999).

Suhu: hasil observasi rumah responden berdasar suhu dari 67 responden $28 \quad(41,7 \%)$ rumah tidak memenuhi persyaratan kesehatan. Sedangkan $39 \quad(58,2 \%) \quad$ memenuhi persyaratan. Rata-rata suhu rumah yang tidak memenuhi syarat $32,17^{\circ} \mathrm{C}$ dan rumah yang memenuhi persyaratan suhunya $29,3^{\circ} \mathrm{C}$. Suhu ruangan yang ideal dalam rumah berkisar $18-20^{\circ} \mathrm{C}$ dan suhu tersebut dipengaruhi oleh suhu udara luar, 
pergerakan udara, dan kelembaban ruangan udara (Ditjen PPM dan PL, 2012).

Pencahayaan: Hasil observasi rumah responden berdasar pencahayaan dari 67 responden $44 \quad(65,7 \%)$ rumah tidak memenuhi persyaratan kesehatan. Sedangkan 23 (34,3\%) rumah memenuhi persyaratan. Rata-rata hasil pengukuran pencahayaan di rumah responden yang tidak memenuhi syarat 20,28 lux dan yang memenuhi syarat 67 lux. Pencahayaan alam dan atau buatan langsung maupun tidak langsung dapat menerangi seluruh ruangan minimal intensitasnya 60 lux dan tidak menyilaukan (Ditjen PPM dan PL, 2012).

Pertukaran udara: hasil observasi rumah responden berdasar pertukaran udara dari 67 responden, 33 (49,2\%) rumah tidak memenuhi persyaratan kesehatan. Rata-rata pertukaran udara di rumah responden yang tidak memenuhi syarat $0,31 \mathrm{~m} /$ detik dan rumah yang memenuhi syarat 0,086 $\mathrm{m} /$ det Sedangkan $34(50,8 \%)$ rumah responden sudah memenuhi persyaratan.

Kecepatan aliran udara penting untuk mempercepat pembersihan udara ruangan. Kecepatan udara dikatakan sedang jika gerak udara 5-20 cm/detik atau volume pertukaran udara bersih antara 20-30 cfm (cubic feet per minute) untuk setiap orang yang berada di ruangan (Ditjen PPM dan $\mathrm{PL}, 2012$ ).

2. Hubungan Lingkungan Fisik Rumah Dengan Kejadian ISPA.

\section{Hubungan Jenis lantai dengan kejadian ISPA}

Jumlah responden penderita ISPA yang lantai rumahnya memenuhi persyaratan 12 (24\%) rumah. Sedangkan yang tidak memenuhi persyaratan 38 rumah (76\%).Berdasarkan perhitungan odds ratio didapatkan nilai $\mathrm{OR}=4,52$ yang berarti kondisi lantai rumah responden yang tidak memenuhi persyaratan 4,52 kali lebih beresiko menimbulkan penyakit ISPA. Hasil uji statistik chi squareangka p-value0,008 $<$ a $(0,05)$ dapat disimpulkan terdapat hubungan variabel jenis lantai rumah dengan kejadian ISPA.

Lantai rumah yang terbuat dari tanah lebih mudah lembab sehingga dapat menjadi sumber penularan penyakit bagi penghuninya. Konstruksi rumah dan lingkungan yang tidak memenuhi syarat kesehatan merupakan faktor resiko penularan berbagai jenis penyakit (Ditjen PPM dan PL, 2012).
Hubungan jenis dinding dengan kejadian ISPA

Jumlah responden penderita ISPA yang dinding rumahnya memenuhi persyaratan 15 (30\%) rumah. Sedangkan yang tidak memenuhi persyaratan 35 (70\%) rumah.

Dinding rumah yang memenuhi syarat adalah dinding yang kedap air, kuat dan mudah dibersihkan. Konstruksi rumah dan lingkungan yang tidak memenuhi syarat kesehatan merupakan faktor resiko penularan berbagai jenis penyakit (Ditjen PPM dan PL, 2012).

\section{Hubungan luas ventilasidengan kejadian ISPA}

Jumlah responden penderita ISPA yang luas ventilasi rumahnya memenuhi persyaratan 20 (40\%) rumah. Sedangkan jumlah yang tidak memenuhi persyaratan $30(60 \%)$ rumah.

Berdasar perhitungan odds ratio didapatkan nilai $\mathrm{OR}=4,875$ yang berarti luas ventilasi rumah responden yang tidak memenuhi persyaratan 4,875 kali lebih beresiko menimbulkan penyakit ISPA. Hasil uji statistik chi squaremenunjukkan angka pvalue $0,009<\mathrm{a}(0,05)$ dapat disimpulkan terdapat hubungan antara variabel luas ventilasi rumah dengan kejadian ISPA.

Luas ventilasi atau penghawaan alamiah yang permanen minimal $10 \%$ dari luas lantai. Ventilasi dapat berupa ventilasi alami yang permanen atau dapat juga memanfaatkan exhauster sehingga sirkulasi udara berlangsung dengan lancar. Pengaruh buruk berkurangnya ventilasi adalah berkurangnya kadar oksigen, bertambahnya kadar gas CO2 adanya bau pengap, suhu udara ruangan naik, dan kelembaban uadara ruangan bertambah.

\section{Hubungan tingkat kepadatan penghuni dengan kejadian ISPA}

Jumlah responden penderita ISPA yang tingkat kepadatan hunian di rumahnya memenuhi persyaratan 41 (82\%) rumah. Sedangkan yang tidak memenuhi persyaratan adalah $9(18 \%)$ rumah.

Berdasar perhitungan odds ratio didapatkan nilai $\mathrm{OR}=3,512$ yang berarti kepadatan hunian dalam rumah responden yang tidak memenuhi persyaratan 3,512 kali lebih beresiko menimbulkan penyakit ISPA. Hasil uji statistik chi squaremenunjukkan angka p-value0,226 >a $(0,05)$ dapat disimpulkan tidak terdapat hubungan antara variabel kepadatan penghuni dalam rumah dengan kejadian ISPA.

Kepadatan penghuni merupakan luas lantai dalam rumah dibagi dengan jumlah 
anggota keluarga penghuni. Berdasar ketentuan kepadatan penghuni dikategorikan menjadi standar (2 orang per $8 \mathrm{~m}^{2}$ ) dan kepadatan tinggi apabila lebih dari 2 orang per $8 \mathrm{~m}^{2}$ (Kepmenkes, 1999). Rumah yang padat penghuninya akan mempermudah penularan penyakit di antara penghuninya, terutama penyakit menular yang penularannya secara direct contactmaupun droplet spread, dan ISPA merupakan penyakit infeksi yang ditularkan melalui droplet spread,sehingga kondisi ini memudahkan anak untuk terkena ISPA (Departemen Kesehatan RI, 2002).

\section{Hubungan kelembaban dengan kejadian ISPA \\ Jumlah responden penderita ISPA yang} kelembaban rumahnya memenuhi persyaratan 21 (42\%) rumah. Sedangkan yang tidak memenuhi persyaratan 29 (58\%) rumah.

Berdasar perhitungan odds ratio didapatkan nilai $\mathrm{OR}=3,314$ yang berarti kelembaban dalam rumah responden yang tidak memenuhi persyaratan 3,314 kali lebih beresiko menimbulkan penyakit ISPA. Hasil uji statistik chi squaremenunjukkan angka p-value $0,042<a(0,05)$ dapat disimpulkan terdapat hubungan antara variabel kelembaban dalam rumah dengan kejadian ISPA.

Kelembaban udara berkisar antara 40\%$60 \%$. Konstruksi rumah yang tidak baik seperti atap yang bocor, lantai dan dinding yang tidak kedap air serta kurangnya pencahayaan baik buatan maupun alami merupakan faktor resiko kelembaban rumah yang tidak memenuhi syarat kesehatan. Kelembaban yang terlalu tinggi maupun rendah dapat menyebabkan suburnya pertumbuhan mikroorganisme (Departemen Kesehatan RI, 2002).

\section{Hubungan suhu dengan kejadian ISPA} Jumlah responden penderita ISPA yang suhu rumahnya memenuhi persyaratan 17 $34 \%$ rumah. Sedangkan yang tidak memenuhi persyaratan $33(66 \%)$ rumah.

Berdasar perhitungan odds ratio didapatkan nilai $\mathrm{OR}=3,55$ yang berarti suhu dalam rumah responden yang tidak memenuhi persyaratan 3,55 kali lebih beresiko menimbulkan penyakit ISPA. Hasil uji statistik chi squaremenunjukkan angka pvalue $0,027<a \quad(0,05)$ dapat disimpulkan terdapat hubungan antara variabel suhu dalam rumah dengan kejadian ISPA pada balita.

Suhu ruangan yang ideal dalam rumah berkisar antara $18-20^{\circ} \mathrm{C}$ dan suhu tersebut dapat dipengaruhi oleh suhu udara luar, pergerakan udara dan kelembaban ruangan udara. Suhu dalam ruang rumah yang terlalu rendah dapat menyebabkan gangguan kesehatan hingga hypotermia, sedangkan suhu yang terlalu tinggi dapat menyebabkan dehidrasi sampai dengan heat stroke (Departemen Kesehatan RI, 2002)

\section{Hubungan pencahayaan dengan kejadian ISPA}

Jumlah responden penderita ISPA yang pencahayaan di dalam rumahnya memenuhi persyaratan $13(26 \%)$ rumah. Sedangkan yang tidak memenuhi persyaratan 37 (74\%) rumah.

Berdasar perhitungan odds ratio didapatkan nilai $\mathrm{OR}=4,06$ yang berarti pencahayaan dalam rumah responden yang tidak memenuhi persyaratan 4,06 kali lebih beresiko menimbulkan penyakit ISPA. Hasil uji statistik Chi squaremenunjukkan angka p-value0,014 <a $(0,05)$ dapat disimpulkan terdapat hubungan antara variabel pencahayaan dalam rumah dengan kejadian ISPA pada balita.

Nilai pencahayaan (Lux) yang terlalu rendah akan berpengaruhterhadap proses akomodasi mata yang terlalu tinggi, sehingga akanberakibat terhadap kerusakan retina pada mata.Cahaya yang terlalu tinggi akan mengakibatkan kenaikan suhu padaruangan.

Pencahayaan dalam rumah diusahakan agar sesuai dengan kebutuhan untuk melihat benda di sekitar dan membaca berdasarkan persyaratan minimal 60 lux. Pencahayaan dapat bersumber dari cahaya alami maupun buatan. Cahaya alami dari matahari pada siang hari berguna untuk mengurangi kelembaban ruang, mengusir nyamuk, membunuh kuman penyebab penyakit tertentu seperti TBC, infuenza dan penyakit lainnya (Departemen Kesehatan RI, 2002).

\section{Hubungan Pertukaran udara dengan kejadian ISPA}

Jumlah responden penderita ISPA dengan pertukaran udara di dalam rumahnya memenuhi persyaratan 21 (42\%) rumah. Sedangkan yang tidak memenuhi persyaratan $29(58 \%)$ rumah.

Berdasar perhitungan odds ratio didapatkan nilai $\mathrm{OR}=4,48$ yang berarti pertukaran udara dalam rumah responden yang tidak memenuhi persyaratan 4,48 kali lebih beresiko menimbulkan penyakit ISPA. Hasil uji statistik chi squaremenunjukkan angka p-value0,014 <a $(0,05)$ dapat disimpulkan 
terdapat hubungan antara variabel pertukaran udara dalam rumah dengan kejadian ISPA pada balita.

Pertukaran hawa (ventilasi) yaitu proses penyediaan udara segar dan pengeluaran udara kotor secara alamiah atau mekanis harus cukup. Kecepatan aliran udara penting untuk mempercepat pembersihan udara ruangan. Kecepatan uadara dikatakan sedang jika gerak udara 5-20 $\mathrm{cm} /$ detik atau volume pertukaran udara bersih antara 20-30 cfm (cubic feet per minute) untuk setiap orang yang berada di ruangan.Pertukaran udara yang tidak memenuhi syarat dapat menyebabkan suburnya pertumbuhan mikroorganisme, yang mengakibatkan gangguan terhadap kesehatan manusia (Departemen Kesehatan RI, 2002).

\section{Analisis Hubungan Lingkungan Fisik Rumah Dengan Kejadian ISPA.}

Jumlah responden penderita ISPA dengan lingkungan fisik di rumahnya memenuhi persyaratan $11(16,4 \%)$ rumah. Sedangkan yang tidak memenuhi persyaratan adalah $39(58,2 \%)$ rumah.

Berdasar perhitungan odds ratio didapatkan nilai $\mathrm{OR}=1,93$ yang berarti lingkungan fisik rumah responden yang tidak memenuhi persyaratan 1,93 kali lebih beresiko menimbulkan penyakit ISPA. Hasil uji statistik chi squaremenunjukkan angka p-value0,001 <a $(0,05)$ dapat disimpulkan 5. $33(49,3 \%)$ rumah tidak memenuhi syarat, $34(50,7 \%)$ memenuhi syarat, ada hubungan kelembaban rumah dengan kejadian ISPA.

6. $39(58,2 \%)$ rumah tidak memenuhi syarat, $28(41,7 \%)$ memenuhi syarat, ada hubungan suhu rumah dengan kejadian ISPA.

7. $44(65,7 \%)$ rumah tidak memenuhi syarat, $23(34,3 \%)$ memenuhi syarat, ada hubungan antara pencahyaan rumah dengan kejadian ISPA.

8. $33(49,2 \%)$ rumah tidak memenuhi syarat, $34(50,8 \%)$ memenuhi syarat, ada hubungan antara pertukaran udara rumah dengan kejadian ISPA.

9. $11(16,4 \%)$ rumah memenuhi syarat (rumah sehat), $39(58,2 \%)$ rumah tidak

\section{DAFTAR PUSTAKA}

Departemen Kesehatan RI. 2002. Pedoman Program Pemberantasan Penyakit ISPA Untuk Penanggulangan ISPA Pada Balita. Jakarta: Departemen Kesehatan RI. terdapat hubungan antara lingkungan fisik rumah dengan kejadian ISPA pada balita.

Rumah merupakan salah satu kebutuhan pokok manusia, disamping kebutuhan sandang dan pangan. Oleh karena itu rumah haruslah sehat dan nyaman agar penghuninya dapat berkarya untuk meningkatkan produktivitas. Konstruksi rumah dan lingkungan yang tidak memenuhi syarat kesehatan merupakan faktor resiko

sumber penularan berbagai jenis penyakit, khususnya penyakit yang berbasis lingkungan, seperti ISPA, Tubercolosis, dll (PPM \& PL, 2012).

\section{KESIMPULAN}

1. $45(67 \%)$ rumah tidak memenuhi syarat, $22(32,9 \%)$ memenuhi syarat, ada hubungan jenis lantai rumah dengan kejadian ISPA.

2. $41(61,1 \%)$ rumah tidak memenuhi syarat, $26(38,9 \%)$ memenuhi syarat, ada hubungan jenis dinding rumah dengan kejadian ISPA.

3. $34(50,7 \%)$ rumah tidak memenuhi syarat, $33(49,3 \%)$ memenuhi syarat, ada hubungan luas ventilasi rumah dengan kejadian ISPA.

4. $10(14,9 \%)$ rumah tidak memenuhi syarat, $57(85,1 \%)$ memenuhi syarat, tidak ada hubungan kepadatan penghuni rumah dengan kejadian ISPA.

memenuhi syarat (tidak sehat), ada hubungan kondisi lingkungan fisik rumah dengan kejadian ISPA.

\section{SARAN}

1. Bagi Dinas Kesehatan Dan Puskesmas, kegiatan penyuluhan dan pemantauan kesehatan rumah yang sudah dilaksanakan untuk dapat dipertahankan bahkan ditingkatkan.

2. Bagi responden, sebaiknya membiasakan untuk hidup bersih dan sehat.

3. Bagi peneliti lain, perlu dilakukan penelitian lebih lanjut yang berkaitan dengan penyakit ISPA dan faktor lingkungan lain yang menjadi resiko penularan ISPA.

Departemen Kesehatan RI. 2012. Profil Kesehatan Indonesia. Jakarta: Departemen Kesehatan RI.

Ditjen PPM dan PL. 2002. Pedoman Teknis Penilaian Rumah sehat. Jakarta: Departemen Kesehatan R.I. 
Kepmenkes RI No. 829/Menkes/SK/VII/1999 tentang Persyaratan Kesehatan Perumahan. Jakarta : Departemen Kesehatan R.I.

Notoatmodjo, S. 2003. IImu Kesehatan Masyarakat Prinsip-Prinsip Dasar. Jakarta: Rineka Cipta.

Notoatmodjo, S. 2005. Metodologi Kesehatan. Jakarta: Rineka Cipta.

Notoatmodjo, S. 2007. Promosi Kesehatan dan IImu Perilaku. Jakarta: Rineka Cipta.

Prasetyawati, Arsita Eka. 2012. Kesehatan Ibu dan Anak (KIA) dalam Millenium
Development Goals (MDG'S). Yogyakarta: Nuha Medika.

Dinas Kesehatan Kabupaten Madiun. 2012. Profil Kesehatan Dinas Kesehatan Kabupaten Madiun.

Setyaningsih, E. 2001. Faktor-faktor yang berhubungan dengan angka kejadian ISPA pada balita Pengunjung puskesmas. Semarang: Fakultas Kesehatan Masyarakat, Universitas Diponegoro.

Wawan, A., \& Dewi Maria. 2010. Medical book: Teori dan Pengukuran Pengetahuan. Sikap. Dan Perilaku Manusia. Yogyakarta: Numed 